day 2 in 82/178 (46\%) and day 7 in 128/164 (78\%) patients with complete assessments to date. 131/181 (72\%) of children had known SARS-CoV-2 positive contacts. We observed no cases of multisystem inflammatory syndrome in children.

\begin{tabular}{|c|c|c|}
\hline Indication for testing & Dates of testing & $\begin{array}{l}\text { Number of patients with } \\
\text { positive test/Number of } \\
\text { patients tested }\end{array}$ \\
\hline $\begin{array}{l}\text { Symptomatic patients: any patient with new } \\
\text { onset cough or fever in the prior } 7 \text { days with } \\
\text { or without known contact with person with } \\
\text { COVID-19 }\end{array}$ & $\begin{array}{l}\text { March } 12 \text { to June } 14, \\
2020\end{array}$ & $181 / 2638(6.8 \%)$ \\
\hline $\begin{array}{l}\text { Asymptomatic screening: Prior to any } \\
\text { hospital admission, receiving cancer } \\
\text { chemotherapy, stem cell, or solid organ } \\
\text { transplantation, or prior to surgical or certain } \\
\text { aerosol-generating medical procedures }\end{array}$ & $\begin{array}{l}\text { May 4, to June 14, } \\
2020\end{array}$ & $12 / 2768(0.4 \%)$ \\
\hline $\begin{array}{l}\text { Neonates born to SARS-CoV-2 positive } \\
\text { mothers }\end{array}$ & $\begin{array}{l}\text { March } 12 \text { to June } 14, \\
2020\end{array}$ & $\begin{array}{l}\text { 0/9 at birth ( } 1 \text { infant } \\
\text { became symptomatic with } \\
\text { a positive test at } 5 \text { weeks } \\
\text { of age, included in } \\
\text { 'symptomatic patients' } \\
\text { cohort, Table 2) }\end{array}$ \\
\hline
\end{tabular}

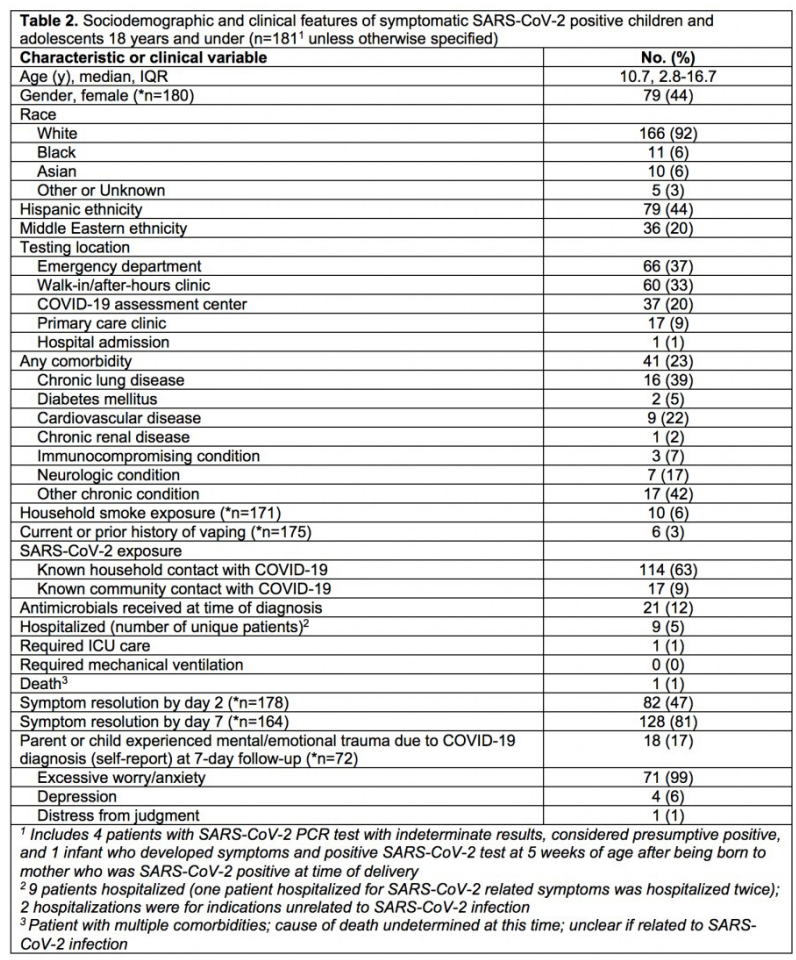

Figure 1. (A) Age group distribution and (B) proportion of patients exhibiting each clinical symptom among symptomatic patients 18 years of age and under with SARS-CoV-2 infection ( $n=181$ except as indicated)

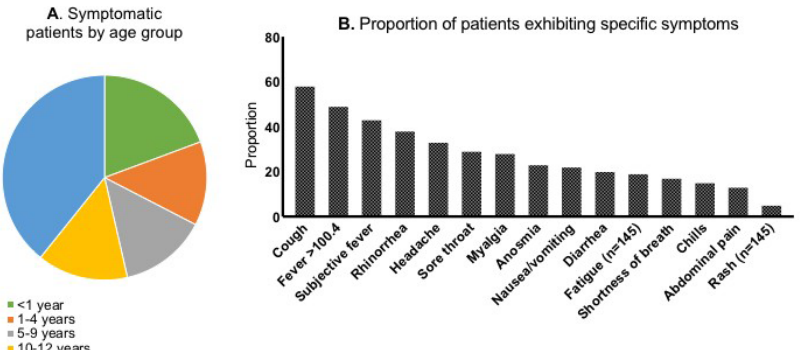

Conclusion: In our community, pediatric SARS-CoV-2 prevalence was low, but was much higher among symptomatic than asymptomatic children. Symptoms were mild, and the duration of symptoms brief, in the majority of these patients captured within an integrated ambulatory and hospital-based healthcare system, capturing the full spectrum of the disease profile in this age group.

Disclosures: Natasha B. Halasa, MD, MPH, Genentech (Other Financial or Material Support, I receive an honorarium for lectures - it's a education grant, supported by genetech)Karius (Consultant)Moderna (Consultant)Quidel (Grant/ Research Support, Research Grant or Support)Sanofi (Grant/Research Support, Research Grant or Support)

359. Ventilator-associated pneumonia in patients with SARS-CoV-2-associated acute respiratory failure requiring mechanical ventilation: a retrospective cohort study

Charles-Edouard Luyt, $\mathrm{Md}, \mathrm{PhD}^{1}$; Pauline Vidal, n/a ${ }^{2}$; Sonia Burrel, $\mathrm{MD}^{2}$;

Guillaume Hekimian, $\mathrm{n} / \mathrm{a}^{2} ;$ Nicolas Brechot, $\mathrm{n} / \mathrm{a}^{2} ;$ Matthieu Schmidt, $\mathrm{MD}^{2}$

Alain Combes, $\mathrm{n} / \mathrm{a}^{2}$; David Boutolleau, $\mathrm{MD}^{2}$; Jérôme Robert, $\mathrm{n} / \mathrm{a}^{2}$; Jean Chastre, n/a $\mathrm{a}^{2}$

${ }^{1}$ Hôpital Pitié-Salpêtrière, Assistance Publique-Hôpitaux de Paris, APHP Sorbonne

Université, Paris, Ile-de-France, France; ${ }^{2}$ Sorbonne Université, Paris, Ile-de-France, France

Session: P-12. COVID-19 Complications, Co-infections, and Clinical Outcomes

Background: Data on incidence, clinical presentation and outcomes of ventilator-associated pneumonia (VAP) in patients with severe coronavirus disease 2019 (COVID-19) pneumonia requiring mechanical ventilation (MV) are limited.

Methods: Case series of patients with COVID-19 pneumonia admitted to a single ICU in France. All consecutive patients requiring MV with RT-PCR-confirmed SARS CoV-2 infection between March 12th and April $24^{\text {th }}, 2020$ were included. Frequency, clinical characteristics, responsible pathogens and outcomes of VAP were assessed, and compared to an historical cohort of patients with severe influenza-associated pneumonia requiring MV admitted to the same ICU during the preceding three winter seasons.

Results: Fifty-four consecutive patients with COVID-19-associated respiratory failure requiring MV were included (median (IQR) age 48 (42-58) years; $74 \%$ male $93 \%$ requiring veno-venous ECMO). VAP occurred in 46 (85\%) of them (median (IQR) prior MV duration before the first episode, 11 (8-16) days) (Table 1). Pathogens responsible for VAP were predominantly Enterobacteriaceae (72\%), and particularly inducible AmpC-cephalosporinase producers (41\%), followed by Pseudomonas aeruginosa (35\%) (Table 2). Pulmonary infection recurrence and death were observed in 46 (85\%) and 17 (31\%) patients, respectively. Details on recurrent episodes and pathogens responsible for recurrences are given in Table 3. Most recurrences were relapse (i.e. infection with the same pathogen), with a high proportion occurring during antimicrobial treatment despite its adequacy. Despite a high rate of $P$. aeruginosa VAP in patients with influenza-associated ARDS, pulmonary infection recurrence rate was significantly lower than in patients with COVID-19. Overall mortality was similar in the two groups.

Baseline characteristics of patients

\begin{tabular}{|c|c|c|}
\hline & $\begin{array}{l}\text { Covid-19 patients } \\
\qquad \mathrm{N}=54\end{array}$ & $\begin{array}{l}\text { Influenza patients } \\
\qquad N=51\end{array}$ \\
\hline Age, yrs* & $48(42-58)$ & $58(48-64)$ \\
\hline Male sex & $40(74)$ & $31(63)$ \\
\hline $\begin{array}{l}\text { Time between symptom onset and ICU admission, } \\
\text { days* }\end{array}$ & $11(7-13)$ & $7(6-11)$ \\
\hline Admission SAPS II score * & $53(45-65)$ & $70(58-79)$ \\
\hline Admission SOFA score * & $12(9-14)$ & $14(9-17)$ \\
\hline Immunosuppressed & $1(2)$ & $6(12)$ \\
\hline $\begin{array}{l}\text { Documented bacterial co-infection at ICU } \\
\text { admission* }\end{array}$ & $10(19)$ & $21(41)$ \\
\hline Antimicrobial treatment at ICU admission & $54(100)$ & $51(100)$ \\
\hline Duration of antimicrobial treatment, days & $5(4-6)$ & $4(2-7)$ \\
\hline $\begin{array}{l}\text { Antiviral agents } \\
\text { Remdesivir } \\
\text { Lopinavir/ritonavir } \\
\text { Hydroxychloroquine } \\
\text { Oseltamivir }\end{array}$ & $\begin{array}{l}6(11) \\
12(22) \\
22(41) \\
2(4)\end{array}$ & $\begin{array}{c}0 \\
0 \\
0 \\
51(10)\end{array}$ \\
\hline ARDS & $54(100)$ & $51(100)$ \\
\hline ECMO & $50(93)$ & $45(88)$ \\
\hline Patients with at least one VAP episode * & $46(85)$ & $31(61)$ \\
\hline $\begin{array}{l}\text { Number of VAP episode per patient * } \\
\quad 1 \\
2 \\
3 \\
\geq 4\end{array}$ & $\begin{array}{l}46(85) \\
35(65) \\
21(39) \\
11(20)\end{array}$ & $\begin{array}{l}31(61) \\
18(35) \\
9(18) \\
4(8)\end{array}$ \\
\hline Duration of ECMO support, days & $21(10-31)$ & $18(8-31)$ \\
\hline Duration of MV, days* & $42(24-53)$ & $24(13-38)$ \\
\hline ICU length of stay, days* & $43(28-58)$ & $29(18-46)$ \\
\hline ICU mortality rate, days & $19(35)$ & $20(39)$ \\
\hline
\end{tabular}

Characteristics of first ventilator-associated pneumonia episode 


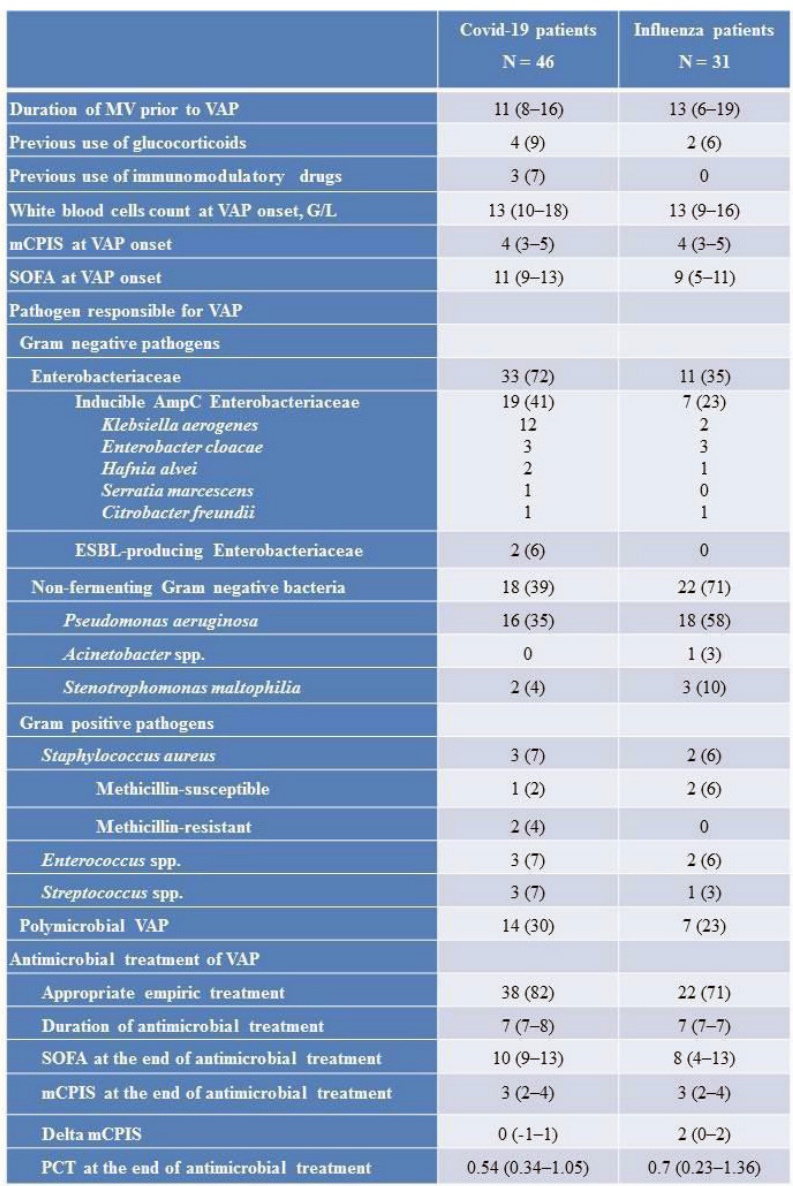

Characteristics of recurrent VAP episodes in Covid-19 and influenza patients.

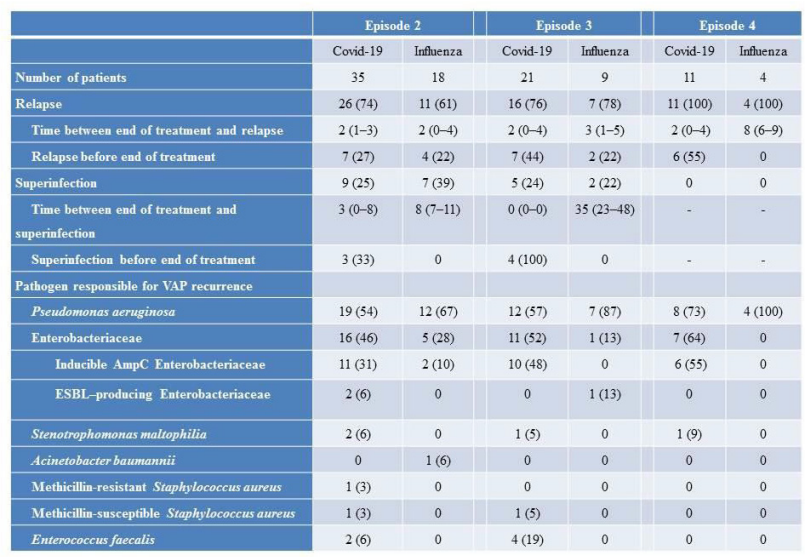

Conclusion: Patients with severe COVID-19-associated respiratory failure requiring MV had a very high late-onset VAP rate. Inducible AmpC cephalosporinaseproducing Enterobacteriaceae and Pseudomonas aeruginosa appeared to be frequently responsible for VAP, with multiple subsequent episodes and difficulties to eradicate the pathogen from the lung.

Disclosures: All Authors: No reported disclosures
360. A Case Control Study of COVID-19 in Patients with End Stage Renal Disease (ESRD)

Su Lin Lim, MD ${ }^{1}$; Kok Hoe Chan, $\mathrm{MD}^{1}$; Sudha Lagudu, $\mathrm{MD}^{2}$; Maria Szabela, MD ${ }^{1}$; Jihad Slim, MD ${ }^{3} ;{ }^{1}$ St. Michael's Medical Center, New Jersey, New Jersey; ${ }^{2}$ St. Michael Medical Center, New Jersey, New Jersey; ${ }^{3}$ Saint Michael's Medical Center, Newark, New Jersey

Session: P-12. COVID-19 Complications, Co-infections, and Clinical Outcomes

Background: COVID-19 is a major global pandemic. Since the first case reported in Wuhan, China, COVID-19 has spread across the globe with more than 7.6 million individuals affected worldwide. Several studies have tried to investigate the risk factors for mortality but there has bot been a definitive study in patients with ESRD. Herein we aimed to investigate whether ESRD is associated with mortality as compared to age, gender and comorbidities matched cohorts.

Methods: A retrospective case control study was performed on patients 18-yearold with confirmed SARS-CoV-2 admitted to our hospital during the study period $(03 / 15 / 2020$ to $05 / 15 / 2020)$. Demographic, characteristics and clinical outcome were retrieved and reviewed. We found 39 ESRD patients, we matched them for 5 variables: Age, gender, diabetes mellitus (DM), hypertension (HTN), and body mass index (BMI). Age was stratified into 3 groups $(<30,30$ to $60,>60)$, history of DM and HTN were defined by reviewing the admission medications, and BMI was divided into 2 categories $(<30$ and $30 \mathrm{~kg} / \mathrm{m} 2)$. The primary endpoint was percentage of inpatient mortality.

Results: We had 39 ESRD patients with COVID-19 out of the 400 patients admitted during the study period with known clinical outcome. Nineteen patients $(49 \%)$ were between 30 to 60 years old while the rest $(51 \%)$ were older than 60 years old. As for gender, $25(64 \%)$ were males and $14(36 \%)$ females. Additional comorbidities were present in 38 patients with hypertension (92\%) being the most common, followed by DM $(64 \%)$ and $\mathrm{BMI}>30 \mathrm{~kg} / \mathrm{m} 2(49 \%)$. With the 5 variables, we were able to match with 177 controls.

Nineteen individuals expired out of the 39 ESRD patients (49\%), as compared to 46 patients from the 177 matched cohort $(26 \%)$ (z-score $2.80, \mathrm{p}=0.0051$; odds ratio [OR] $2.71 ; 95 \%$ confidence interval [CI], 1.28-5.41)

Conclusion: Our results suggest that ESRD patients is an independent risk factor for increased mortality in patients with COVID 19 disease. Larger prospective studies will need to confirm this finding and try to find ways to mitigate this very high mortality in this vulnerable population.

Disclosures: Jihad Slim, MD, Abbvie (Speaker's Bureau)Gilead (Speaker's Bureau)Jansen (Speaker's Bureau)Merck (Speaker's Bureau)ViiV (Speaker's Bureau)

\section{A Case Control Study of COVID-19 Outcome in Patients with HIV}

Liana Atallah, MD, $\mathrm{MPH}^{1}$; Kok Hoe Chan, $\mathrm{MD}^{1}$; Kayla M. Natali, PharmD, AAHIVP ${ }^{1}$; Sindhu Nagarakanti, n/a ${ }^{2}$; Jihad Slim, MD $^{1}$; ${ }^{1}$ Saint Michael's Medical Center, Newark, New Jersey; ${ }^{2}$ Saint Michael's Medical Center, Basking Ridge, New Jersey

Session: P-12. COVID-19 Complications, Co-infections, and Clinical Outcomes

Background: Little is known regarding outcome of patients living with HIV (PLWH) when they get admitted to a hospital for Severe Acute Respiratory Syndrome Coronavirus 2 (SARS-CoV-2) infection. We decided to conduct a case-controlled study to try to answer the question if PLWH are at higher risk of mortality compared to individuals without HIV infection but with the same risk factors that affects outcome in COVID-19 disease.

Methods: A retrospective case matched control study was performed from $03 / 15 / 2020$ to $05 / 15 / 2020$. We reviewed all confirmed SARS-CoV-2 infected patients who were admitted to our hospital during the study period and retrieved 7 variables: Age, gender, diabetes mellitus (DM), hypertension (HTN), body mass index (BMI) chronic kidney disease (CKD), HIV status. We divided the age in 3 groups $(<30,30$ to $60,>60)$, we defined the presence of DM and HTN by reviewing the admission medications, BMI $>30$ defined obesity, and CKD was present if eGFR $<45 \mathrm{ml} / \mathrm{min}$ prior to the current admission. We found $12 \mathrm{PLWH}$, we matched them for the 6 variables, we found 94 controls. The primary endpoint was percentage of inpatient mortality.

Results: Of the 436 confirmed SARS-CoV-2 infection admitted between $03 / 15 / 20$ and 05/15/20, 36 were still hospitalized. Twelve were PLWH out of the 400 patients with known outcome; 7 patients (58\%) have the age range between 30 to 60 years old while the rest $(42 \%)$ have age $>60$ years old. Male to female ratio was $1: 1$ (6 patients each). Comorbidities were present in 10 patients (83\%) with HTN (83\%) being the most common, followed by CKD (58\%), obesity (33\%), and DM (33\%).

Only 1 patient expired out of the 12 PLWH (8\%) admitted with COVID-19, as compared to 26 patients from the 98 matched cohort $(27 \%)$ ( $\mathrm{z}$-score $1.38, \mathrm{p}=0.17$; odds ratio $[\mathrm{OR}], 3.972 ; 95 \%$ confidence interval $[\mathrm{CI}], 0.62-44.37)$. 